\title{
SEISMIC FRAGILITY ASSESSMENT OF STEEL LIQUID STORAGE TANKS
}

\author{
Konstantinos Bakalis \\ National Technical University of Athens \\ School of Civil Engineering \\ Athens, Greece \\ email: kbakalis@mail.ntua.gr
}

\author{
Dimitrios Vamvatsikos \\ National Technical University of Athens \\ School of Civil Engineering \\ Athens, Greece \\ email: divamva@mail.ntua.gr
}

\author{
Michalis Fragiadakis \\ National Technical University of Athens \\ School of Civil Engineering \\ Athens, Greece \\ email: mfrag@mail.ntua.gr
}

\begin{abstract}
A seismic fragility assessment procedure is developed for atmospheric steel liquid storage tanks. Appropriate system and component-level damage states are defined by identifying the failure modes that may occur during a strong ground motion. Special attention is paid to the elephant's foot buckling failure mode, where the estimation of the associated capacity and demand requires thorough consideration within a probabilistic framework. A novel damage state is introduced to existing procedures with respect to the uncontrollable loss of containment scenario. Fragility curves are estimated by introducing both aleatory and epistemic sources of uncertainty, thus providing a comprehensive methodology for the seismic risk assessment of liquid storage tanks. The importance of dynamic buckling is acknowledged and the issue of non-sequential damage states is finally revealed.
\end{abstract}

\section{INTRODUCTION}

Oil \& Gas products are normally stored in large-capacity atmospheric tanks. Safeguarding the integrity of such industrial facilities against earthquakes is vital not only for maintaining the flow of essential products and energy resources, but also for preventing any associated socioeconomic consequences. Ensuring an "appropriate" level of safety tantamount to the importance of liquid storage tanks, mandates the use of state-ofthe-art techniques that take into account all possible sources of uncertainty, in the form of Performance-Based Earthquake Engineering (PBEE).

The assessment methodology typically undertaken by engineers is based on the design code and can be summarised in a prescriptive approach that may only deliver some acceptable (but actually unknown) level of accuracy by engaging in a deterministic process, where the associated dispersion is either inadequately defined or completely missing. Still, PBEE has reached a mature state in civil engineering structures. On the contrary, no provisions regarding industrial equipment structures exist. Parameters such as the geometry, the toxicity/flammability of the stored materials, and the intrinsic failure modes make the problem substantially different from buildings or bridges where current provisions apply.

The devastating outcome of recent earthquake events such as Kocaeli (1999) and Tohoku (2011), further enhances the view that little attention has been paid to industrial facilities even from an academic perspective. Previous research efforts may be summarised to a fragility-based methodology using either expensive finite element models [1,2], or available empirical data as shown by O'Rourke and So [3]. A systematic PBEE methodology based on a surrogate modelling approach was recently developed by Bakalis et al. [4], thus offering an alternative to the existing procedures.

This study aims to further develop the existing framework by offering extensive information on the "Elephant's Foot Buckling" (EFB) formation and its representation within the seismic risk assessment procedure. A typical case-study liquid storage tank is subjected to a series of nonlinear time-history analyses in view of defining a PBEE framework that pays special attention to the loss of the contained liquid. 


\section{PROBLEM DEFINITION}

Field investigations after major earthquakes have revealed a variety of failure modes on atmospheric tanks. They may be summarised to shell buckling, base sliding and sloshing damage to the upper tank shell and roof. EC8-part 4 [5] provides special provisions for these modes of failure, as shown by Vathi et al. [6]. For instance, when partial uplift is allowed, either for design purposes or due to poor detailing of the anchors, the rotation of the plastic hinge developed on the base plate of the tank should not exceed a certain rotational capacity, specified in EC8. Moreover, the excitation of the long period convective mass may cause sloshing of the contained liquid, which can in turn damage the upper parts of the tank (roof, upper wall course). During strong ground motion events, hydrostatic and hydrodynamic effects may lead to high internal pressure on the tank walls. Overturning for those thin shell structures is resisted by compressive meridional stresses on the wall. Although high pressure may increase the capacity against buckling by introducing high hoop stress, local yielding may trigger an elastic-plastic buckling failure around the lower course of the tank's perimeter, known as the "Elephant's Foot Buckling" (Fig. 1).

The most damaging failure modes are mainly associated with plate/shell rupture, as they may result in loss of the contained liquid. Rupturing either the bottom layers of the tank wall or the base plate is expected to trigger an uncontrolled loss of the stored material, with all the associated consequences considered. Examining the aforementioned problem under a binary (i.e. deterministic) perspective may induce additional conservatism, as the EFB formation upon a nozzle or a manhole is more likely to lead to loss of containment by far. On the other hand, EFB may render a tank unusable when developed between two consecutive manholes, yet the probability of leakage is expected to be a lot smaller. It is evident that the tank wall rupture is strongly tied to the location, or in other words the extent of the EFB failure along the circumference of the tank.

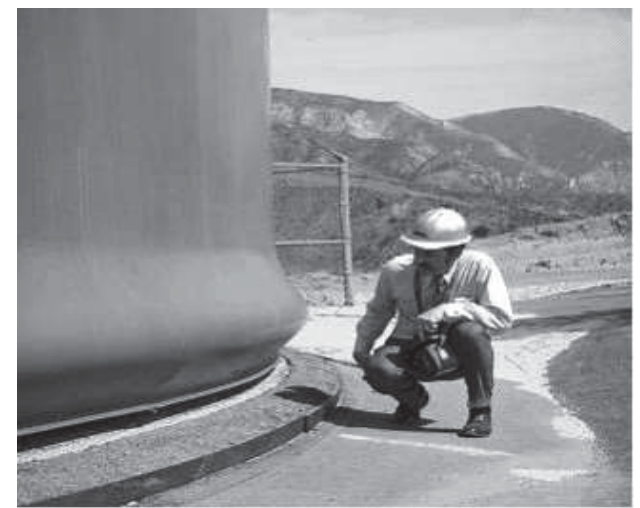

Fig. 1: "Elephant's Foot Buckling" failure mode

\section{CASE STUDY DESCRIPTION}

In an attempt to capture the seismic risk involved in a liquid storage tank, a structural system with the following geometric characteristics is adopted. The tank considered has a radius $(R)$ equal to $13.9 \mathrm{~m}$ and a total height $\left(h_{t}\right)$ of $16.5 \mathrm{~m}$. The bottom course wall $\left(t_{w}\right)$ is $17.7 \mathrm{~mm}$ thick, while the corresponding base plate $\left(t_{b}\right)$ and annular ring $\left(t_{a}\right)$ thickness are $6.4 \mathrm{~mm}$ and $8.0 \mathrm{~mm}$ respectively. The fluid stored in the tank is assumed to reach the maximum allowable fluid height of $h_{f}=14 \mathrm{~m}$, resulting to a 'fluid height over radius' ratio $\left(h_{f} / R\right)$ equal to 1.01 .

\section{EXISTING PBEE FRAMEWORK}

A seismic reliability assessment methodology for liquid storage tank was recently developed by Bakalis et al. [4]. It provides all necessary information to derive fragility curves both for a single liquid storage system and a group of tanks with varying geometric characteristics. The seismic risk assessment procedure is based on a surrogate modelling approach in view of the balanced "computational efficiency versus accuracy" compromise offered for nonlinear time-history analysis. The modelling approach is based on the work of Malhotra and Veletsos [7] for liquid storage systems, where the uplifting mechanism of unanchored tanks is modelled in detail. A brief summary of the modelling procedure adopted is presented in Fig. 2. One may notice that the convective component of the fluid is not considered in the model. This decision is twofold. Obviously, the contribution of the long-period convective component to the rigid-impulsive response of a broad tank may be deemed negligible [6]. That essentially provides a single rather than a double degree-of-freedom (DOF) system, the efficiency of which can only be appreciated within a probabilistic framework. As a result, the impulsive mass $\left(m_{i}\right)$ of the system is connected to the base using an elastic element, as shown in Fig. 2(a). The base plate is modelled using rigid beams that are supported on elastic multilinear springs that simulate the uplifting resistance for each of the ' $N$ ' beam-spokes, representing equal-area sectors of the circular base plate. The deflected shape shown in Fig. 2(b) presents the uplifting mechanism of the tank, where the base shear $\left(V_{b}\right)$ induces a certain amount of uplift $(w)$ on the beamspokes of the model. The aforementioned mechanism offers the ability to estimate all major modes of failure, when they are expressed as a function of uplift. Sloshing response on the other hand is only affected by parameters such as the convective mass of the fluid and the available freeboard, and may be calculated though a simple response spectrum analysis for the convective component, following the EN1998 [5] provisions.

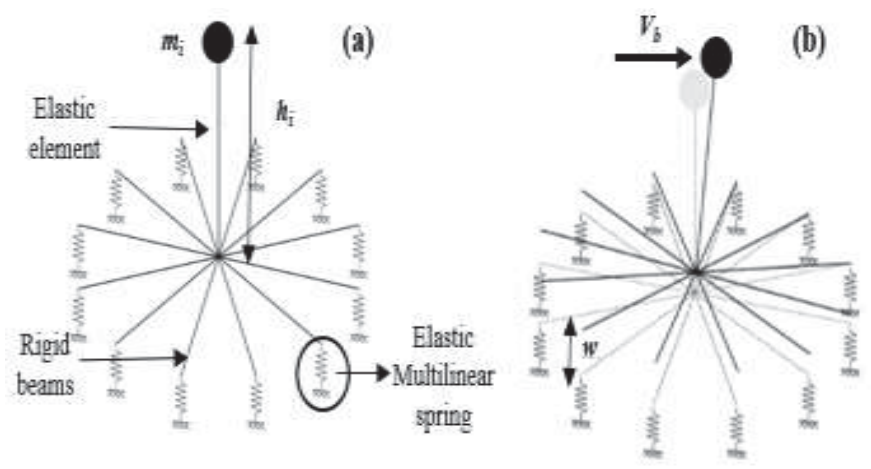

Fig. 2: (a) Tank model and (b) its deflected shape 
The most damaging failure modes are the ones that may result in loss of containment, while others are mainly confined to structural damage without leakage. Thus, for the performancebased assessment of atmospheric tanks the PBEE framework considers three damage states of increasing severity, namely minor (DS1), severe without leakage (DS2) and loss of containment (DS3). Although this classification may seem reasonable for roughly understanding the extent of damage, the accurate assessment of loss may become tricky as, for example, the different mechanisms involved in a single damage state may be associated with varying degrees of component damage. For instance, the sloshing height response represents relatively easyto-repair damage at the top of the tank, compared to an exceedance of a plastic rotation limit at the base. Thus, it becomes more informative to also classify damage based on the actual component that has failed. Fig. 3 presents the associated failure modes on the median Incremental Dynamic Analysis (IDA) curve [8] for the unanchored liquid storage tank considered. The FEMA P695 [9] far field ground motion set is used for the nonlinear dynamic analysis. The base uplift is adopted as one of the Engineering Demand Parameters (EDP) and the impulsive period spectral acceleration $\mathrm{S}_{\mathrm{a}}\left(T_{\text {imp }}\right)$ or the peak ground acceleration PGA (similar due to low $T_{\text {imp }}$ ) are employed as suitable Intensity Measures (IM) that adequately capture the response of a liquid storage system. It is evident that a component-based classification of damage is quite informative, where the upper course of the tank ( $\mathrm{SL}=$ sloshing), its lower course $(\mathrm{EFB})$, the base plate $\left(\theta_{\mathrm{pl}}=\right.$ plastic rotation), and the anchors (AN=yielding/fracture of anchors) are individually examined. Failure modes such as buckling and plastic rotation are revealed during the nonlinear time-history analysis. Sloshing damage at the top of the tank wall is also considered. Still, as shown in Fig. 3, this may only appear at excessive spectral acceleration values for large tanks due to the ultra-long convective period $\left(T_{\text {con }}\right)$.

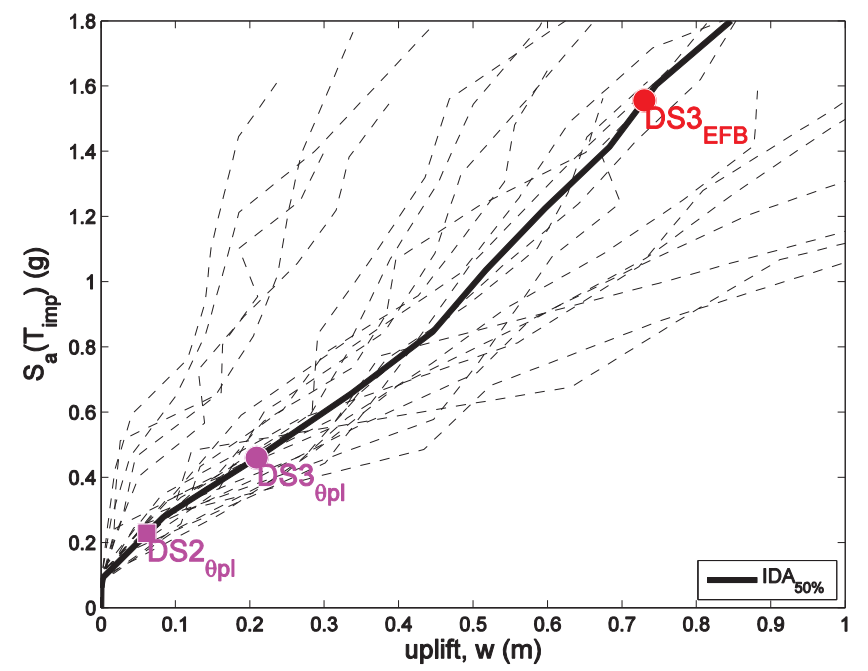

Fig. 3: Single record and median IDA curves for the unanchored tank examined
The classification outlined above may indeed offer a comprehensive reliability assessment procedure for a single liquid storage unit. Under a strong earthquake excitation, however, a group of similar structural systems is expected to suffer consequences ranging from limited structural damage to loss of containment, and thus a global damage state classification should also be considered. In that sense, DS1 represents minor damage induced by a sloshing wave height of the contained liquid equal to the freeboard. DS2 refers to severe damage at any component of the tank without leakage, where the exceedance of either a sloshing wave height equal to 1.4 times the available freeboard or a plastic rotation of 0.2 rad at the base plate triggers the damage state violation. DS3, finally, provides information on the loss of containment through the exceedance of either the axial EFB capacity $\left(\mathrm{N}_{\mathrm{EFB}}\right)$ or the base plate plastic rotation of $0.4 \mathrm{rad}$. As far as anchored systems are concerned, the yielding of the anchors is considered for DS1, while the fracture of the connection for DS2.

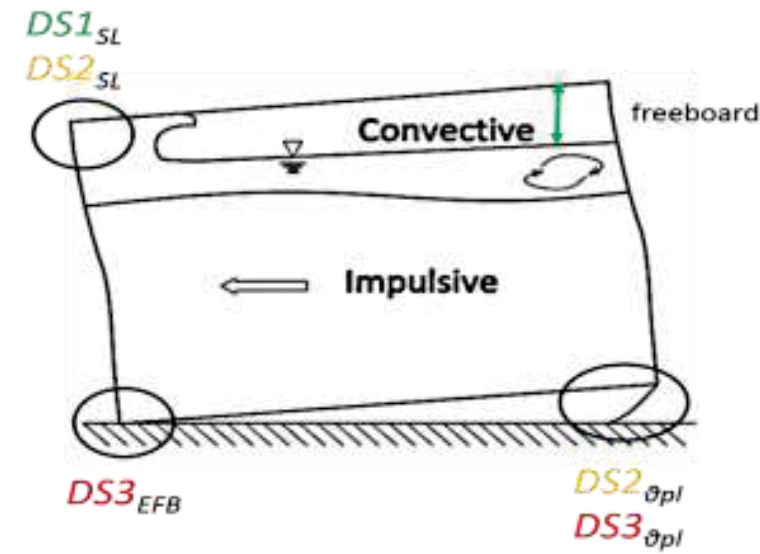

Fig. 4: Global versus Local DS classification for unanchored tanks

\section{BASIC DEFINITION OF LEAKAGE POTENTIAL}

The classification outlined above forms a comprehensive PBEE methodology for the seismic reliability assessment of liquid storage tanks. Still, the treatment of the EFB as well as the plastic rotation manifestation seems rather conservative, as the locations of nozzles or manholes is not currently considered. So far, the exceedance of the aforementioned failure modes is estimated through the EDP response history developed on the edge of the beam-spoke that is uplifted the most.

The definition of DS3 due to EFB introduces components such as nozzles and manholes to the seismic fragility estimation in view of providing a more rational approach towards the damage suffered during a strong ground motion. A uniform distribution for the aforementioned components is considered as shown in Fig. 5. The configuration given below does not capture reality in its entirety, as a variety of piping systems is normally attached on the lower course of the tank, following a distribution pattern that depends on a range of parameters similar to the type 
of the stored material and the petrochemical processes followed within the refinery. However, for the purpose of this study, a simple layout is more than enough to stress out the importance of the proposed methodology.

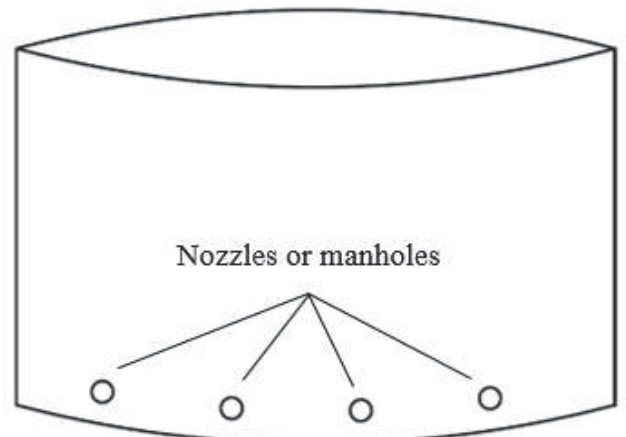

Fig. 5: Tank layout featuring the nozzle/manhole distribution

\section{EFB REPRESENTATION}

A better understanding regarding EFB and its representation within a seismic risk assessment framework is obtained through the Eq. (1) limitation provided by Eurocode 8 [5], where ' $p$ ' is the maximum interior pressure in the seismic design situation. Obviously, the buckling stress is not only a function of the pressure acting on the tank wall but also of the associated wall thickness $\left(t_{w}\right)$, as shown in Eq. (2) and (3).

$\sigma_{m}=\sigma_{c 1}\left[1-\left(\frac{p R}{t_{w} f_{y}}\right)^{2}\right]\left(1-\frac{1}{1.12+r^{1.15}}\right)\left[\frac{r+f_{y} / 250}{r+1}\right]$

$\sigma_{c 1}=0.6 E \frac{t_{w}}{R}$

$r=\frac{R / t_{w}}{400}$

The aforementioned limitation may serve as a useful approximation within a simplified seismic assessment procedure. Its inherently deterministic nature, however, allows for further modifications in an attempt to form a more robust assessment methodology. The latter remark is highlighted through the internal pressure calculation, where the impulsive component is strongly tied to the impulsive mass absolute acceleration response during a strong ground motion [7], as shown in Eq.(4). A cylindrical coordinate system is adopted for the impulsive pressure estimation, using the non-dimensional coordinates $\xi, \zeta, \theta$. Even though this calculation seems quite simple for a given seismic design scenario, it may become very complex when examined from an assessment point of view, as the demand forms a generally increasing function contrary to the capacity that approaches zero for large intensities. In fact, an accurate estimation of the impulsive pressure is only possible in the time domain, as the square root sum of squares (SRSS) rule for the absolute maxima along the $\mathrm{X}$ and $\mathrm{Y}$ earthquake components may lead to unrealistic results. Estimating EFB capacity for a given record and seismic intensity requires thorough consideration not only of the instantaneous magnitude acceleration, but also of the associated directionality in time. Furthermore, only the intersection of the buckling capacity and demand response histories may signal the EFB violation on a given spoke (i.e., sector) in our model. That being said, there is an obvious question regarding capacity and demand estimates for seismic intensities (normally very small accelerations) that allow for a complete separation of the aforementioned time histories. There may not be a straightforward answer to this question, still, one may estimate the capacity-demand combination that is more likely to occur through a simple Monte Carlo simulation.

$$
p_{i}(\xi, \zeta, \theta, t)=C_{i}(\xi, \zeta) \rho H \cos \theta A(t)
$$

A detailed representation of the EFB failure mode is given through Incremental Dynamic Analysis in Fig. 6. Single record IDA curves are displayed using the axial force developed on the beam spokes as an appropriate EDP (black solid lines). They essentially form the EFB demand $\left(E F B_{D}\right)$ for the entire liquid storage system. The grey dotted lines on the other hand, depict the buckling capacity variability $\left(E F B_{C}\right)$ for the given range of IM levels. It appears that the initial buckling capacity (i.e. for a PGA $=0$ ) refers to the static load case of the liquid storage system where the maximum internal pressure equals the corresponding hydrostatic. For larger PGA estimates, the impulsive pressure adds on to the hydrostatic pressure on the compressive side of the tank, which results in a significant reduction of the EFB capacity. Intersection among capacity and demand curves for each record provides the DS $3_{\mathrm{EFB}}$ violation for the global DS classification shown in Fig. 4.

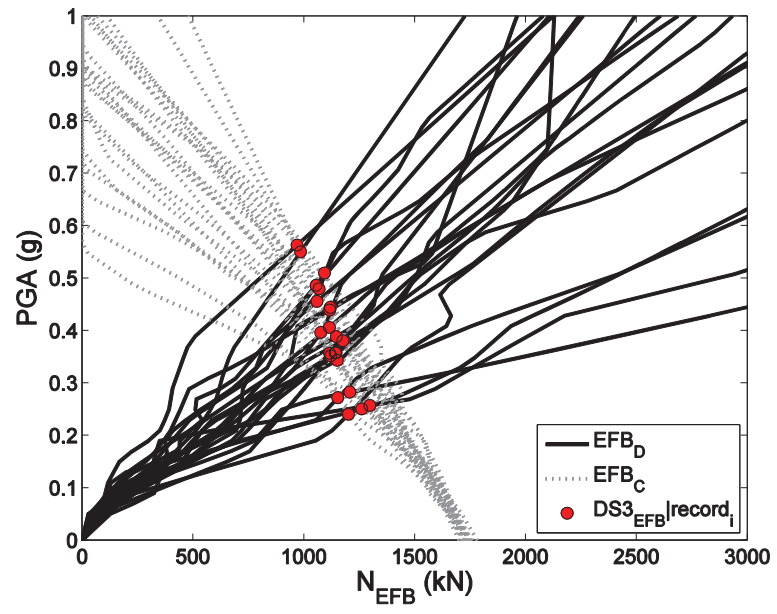

Fig. 6: EFB capacity versus demand as seen through IDA 
Despite the probabilistic approach attempted by Bakalis et al. [4], sources of conservatism are still evident as the DS3 $3_{\mathrm{EFB}}$ violation is built upon the axial capacity exceedance on a single spoke. It appears that a solid prediction cannot be performed following existing methodologies, as the median capacities are either inadequately defined or completely missing. The view developed above is further enhanced through Fig. 7, where the EFB capacity for a given IM level and record is compared to the corresponding demand along the circumference of the tank. It appears that although the buckling zone spreads on a significant number of beam spokes, there are several spots where the capacity has not been reached. Lengthwise, buckling is spread on two nearly identical subzones. One may also notice the symmetry of the failure mode developed on the tank, which can only be attributed to the cyclic loading that the system experiences during a strong ground motion.

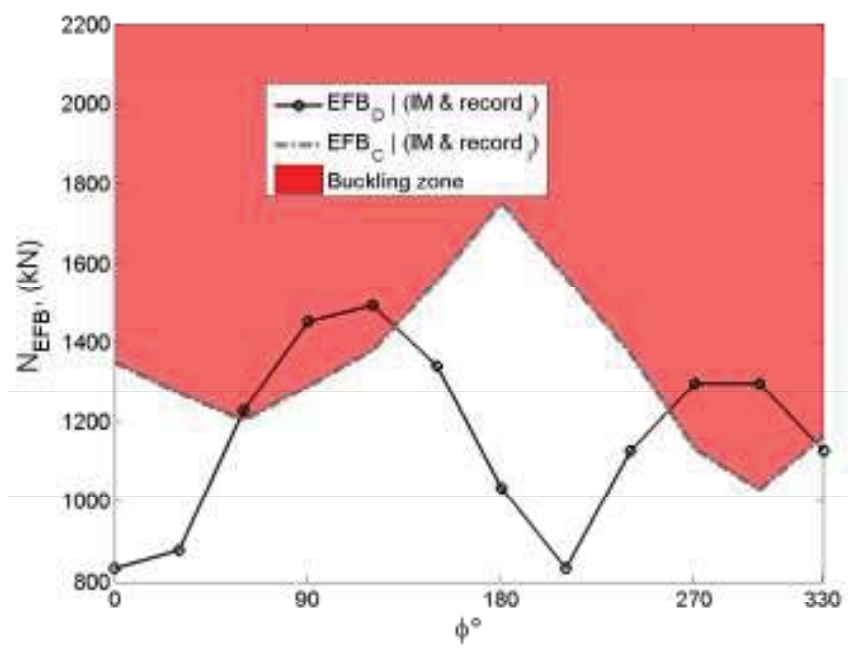

Fig. 7: EFB capacity versus demand along the circumference of the tank, given IM \& record

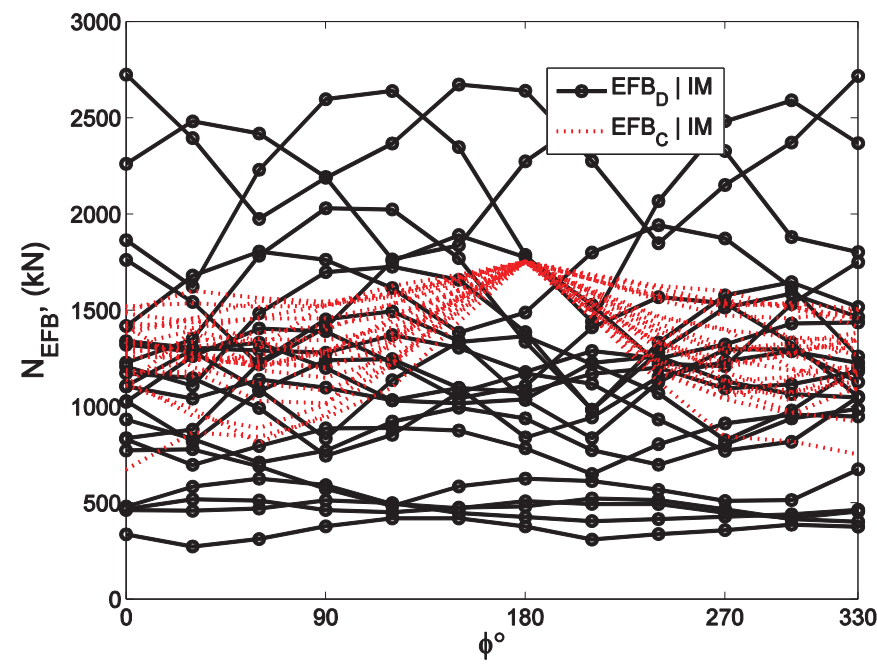

Fig. 8: EFB capacity versus demand along the circumference of the tank, given IM
The EFB capacity and demand along the tank circumference, for a given earthquake intensity, is illustrated on Fig. 8 using the record suite previously adopted for the Incremental Dynamic Analysis. A considerable variability is revealed for the capacity as well as the demand. It seems that the EFB violation is not straightforward, as there are certain records where capacity is not exceeded at any part of the tank, others where every spoke capacity is, and some that follow the partial violation pattern shown in Fig. 7. Evidently, a seismic fragility estimation with respect to the EFB failure mode requires a holistic approach towards capacity and demand of a liquid storage system.

\section{REVISED DEFINITION OF LEAKAGE POTENTIAL}

A more realistic representation of the elephant's foot buckling phenomenon is given through Fig. 9. The results shown in Fig. 6 are compared to a more extensive EFB failure that spreads to five spokes around the tank circumference instead of one. It is the authors' opinion that this illustration is more akin to reality, as according to recent finite element studies [1] it is highly unlikely that the examined buckling mode of failure is restrained to small arc lengths covered by a single spoke. It appears that a new damage state should be adopted for the loss of containment scenario in order to extend the existing seismic risk assessment methodology for liquid storage tanks.

Multiple-spoke EFB failure shall form the basis of the revised DS3 definition. Considering both detailed finite element studies and field investigation observations after significant earthquake shocks, it is believed that an EFB failure that extends from $50 \%$ of the tank circumference and beyond is able to sufficiently capture the uncontrolled loss of containment damage state. The flexibility of the modelling approach adopted allows for the consideration of several scenarios of damage with respect to the loss of the stored material under severe earthquake loading. A more refined discretisation on the base plate of the tank may not modify the response of the model, however it can simulate a smoother representation of the lower course buckling along the circumference of the system, or even provide an alternative damage state classification that is entirely up to the respective client. 


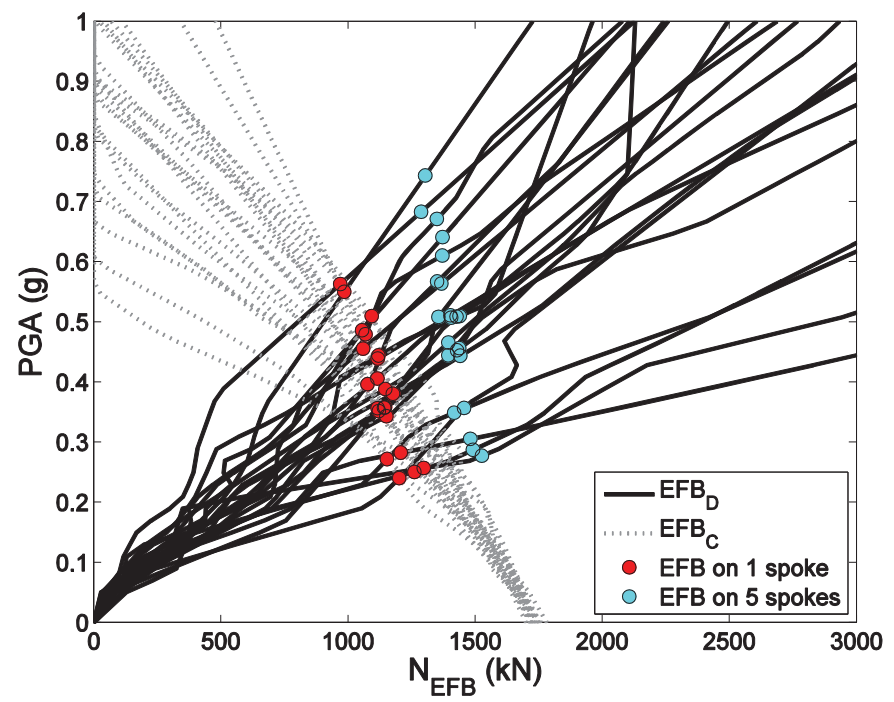

Fig. 9: Single to multiple-spoke EFB failure as seen through IDA

Table 1 provides local damage state capacities for the extended framework developed herein. They may be used to provide detailed seismic risk assessment for a single liquid storage tank. For a more common case where the assessment procedure refers to a group of tanks (within a refinery for example), the aforementioned local capacities are combined in a Global damage state classification with respect to the extent of damage that every single failure mode is capable of. Table 2 summarises the extended Global damage state classification both for anchored and unanchored liquid storage tanks. Built upon an existing seismic reliability assessment methodology [4], the proposed framework verges on a totally undesired level of damage, where a certain tank suffers rapid loss of the stored material.

Table 1: Extended Local damage state classification

\begin{tabular}{c|c}
\hline Local DSi & DS Capacities \\
\hline $\mathrm{DS} 1_{\mathrm{SL}}$ & freeboard \\
$\mathrm{DS}_{\mathrm{AN}}$ & Anchorage yielding $\left(\delta_{\mathrm{y}}\right)$ \\
$\mathrm{DS}_{\mathrm{SL}}$ & $1.4^{*}$ freeboard \\
$\mathrm{DS}_{\mathrm{AN}}$ & Anchorage fracture $\left(\delta_{\mathrm{u}}\right)$ \\
$\mathrm{DS}_{\theta \mathrm{pl}}$ & 0.2 rad \\
$\mathrm{DS}_{\theta_{\mathrm{pl}}}$ & $0.4 \mathrm{rad}$ \\
$\mathrm{DS}_{\mathrm{EFBa}}$ & EFB ( $1^{\mathrm{st}}$ spoke) \\
$\mathrm{DS}_{\mathrm{EFBb}}$ & EFB $(50 \%$ spokes $)$ \\
\hline
\end{tabular}

Table 2: Extended Global damage state classification

\begin{tabular}{|c|c|c|c|}
\hline Tank Description & \multicolumn{2}{|c|}{ Global (DSi) } & DS Capacities \\
\hline \multirow{4}{*}{ Unanchored } & \multicolumn{2}{|c|}{ DS1 } & $\mathrm{DS} 1_{\mathrm{SL}}$ \\
\hline & \multicolumn{2}{|l|}{ DS2 } & $\mathrm{DS} 2_{\mathrm{SL}}$ or $\mathrm{DS} 2_{\theta \mathrm{pl}}$ \\
\hline & \multirow{2}{*}{ DS3 } & $\mathrm{a}$ & $\mathrm{DS}_{\theta \mathrm{pl}}$ or DS3 $3_{\mathrm{EFBa}}$ \\
\hline & & $\mathrm{b}$ & $\mathrm{DS}_{\mathrm{EFBb}}$ \\
\hline \multirow{4}{*}{ Anchored } & \multicolumn{2}{|l|}{ DS1 } & $\mathrm{DS} 1_{\mathrm{SL}}$ or $\mathrm{DS} 1_{\mathrm{AN}}$ \\
\hline & \multicolumn{2}{|l|}{ DS2 } & $\mathrm{DS} 2_{\mathrm{SL}}$ or $\mathrm{DS} 2_{\mathrm{AN}}$ or $\mathrm{DS} 2_{\theta \mathrm{pl}}$ \\
\hline & \multirow{2}{*}{ DS3 } & $\mathrm{a}$ & $\mathrm{DS}_{\theta \mathrm{pl}}$ or DS3 $3_{\mathrm{EFBa}}$ \\
\hline & & $\mathrm{b}$ & $\mathrm{DS}_{\mathrm{EFBb}}$ \\
\hline
\end{tabular}

\section{SEISMIC FRAGILITY ASSESSMENT}

An EDP-based fragility estimation methodology is adopted, where the probability of exceeding a certain limit state capacity for a given level of intensity may be calculated through the ratio of the sum of events that overcome the aforementioned capacity over the number of records used for the IDA. The EDP-based methodology forms a very simple procedure within a probabilistic framework, where the sample capacities are considered lognormally distributed around each limit state median capacity. The probability that the demand exceeds the median limit state capacity, given the intensity measure, may be calculated through the standard normal cumulative distribution function $\Phi$ as shown in Eq. (5), where $E \hat{D} P_{C}$ is the median limit state capacity, $E \hat{D} P_{D}$ is the median demand given $I M$ and $\beta_{E D P_{C}}^{2}$ , $\beta_{E D P_{D}}^{2}$ their associated dispersions.

$P(C<D \mid I M)=\Phi\left(\frac{\ln E \hat{D} P_{D}(I M)-\ln E \hat{D} P_{C}(I M)}{\sqrt{\beta_{E D P_{C}}^{2}+\beta_{E D P_{D}}^{2}}}\right)$

The procedure outlined above provides a robust probability estimation for the majority of the damage state capacities adopted. For the case of DS3b, however, the associated probability of exceedance requires thorough investigation, as the local damage state output is available on a spoke-to-spoke basis. The probability that the EFB capacity is exceeded on a certain number of spokes can only be evaluated under the assumption that the spoke-specific probabilities are independent events. That allows for a direct estimation of the intersection of multiple events. In that sense, if $P_{i}$ is the EFB probability of exceedance of the $i^{\text {th }}$ spoke for a given record and IM level, the desired probability may be estimated through the sum of all possible combinations that satisfy the event constraints. Eq. (6) summarises the concept described above. ' $S$ ' is the number of spokes in the model, ' $X$ ' is the desired number of spokes to experience EFB and ' $N$ ' is the number of the available combinations.

$P(C<D \mid I M$ \& record $)=\sum_{1}^{N} \prod_{i}^{x+i-1} P_{i} \cdot \prod_{x+i-1}^{S-(x+i)}\left(1-P_{S-i}\right)$

In order to accurately assess the seismic risk involved in liquid storage tanks, an intensity measure that characterises the structural system's response in an optimal manner is identified. There has been a lot of discussion within the Earthquake Engineering community regarding which intensity measure better represents the structural response during the seismic risk assessment procedure. According to Luco and Cornell [10] and Shafieezadeh et al. [11], the answer to this question is not distinct, as certain parameters involved in a structural system 
may significantly affect its response, especially when the firstmode load-pattern is not applicable. For the case of liquid storage tanks, the peak ground acceleration (PGA) is a reasonable choice due to the impulsive load pattern adopted in the modelling procedure, even though its convective response can only be accurately estimated through the corresponding convective spectral acceleration. As with the majority of complex structural systems, it is unlikely that a single IM can adequately capture the response and hence other alternatives must be considered. This is an interesting problem that requires a thorough discussion and despite it is beyond the scope of this study, it is expected to be covered in future direction of our research.

A parametric study regarding the extent of EFB damage on liquid storage tanks is presented on Fig. 10. The probability of exceeding certain EFB lengths is plotted versus the intensity measure adopted in order to illustrate the importance as well as the flexibility of the proposed damage state. Significant difference between the curve that represents damage on $50 \%$ of the beam spokes (i.e. DS3b) and the one that refers to the $1^{\text {st }}$ spoke only is observed for practically any given IM level. That verifies our initial speculations concerning a rather rare event which is worth considering though.

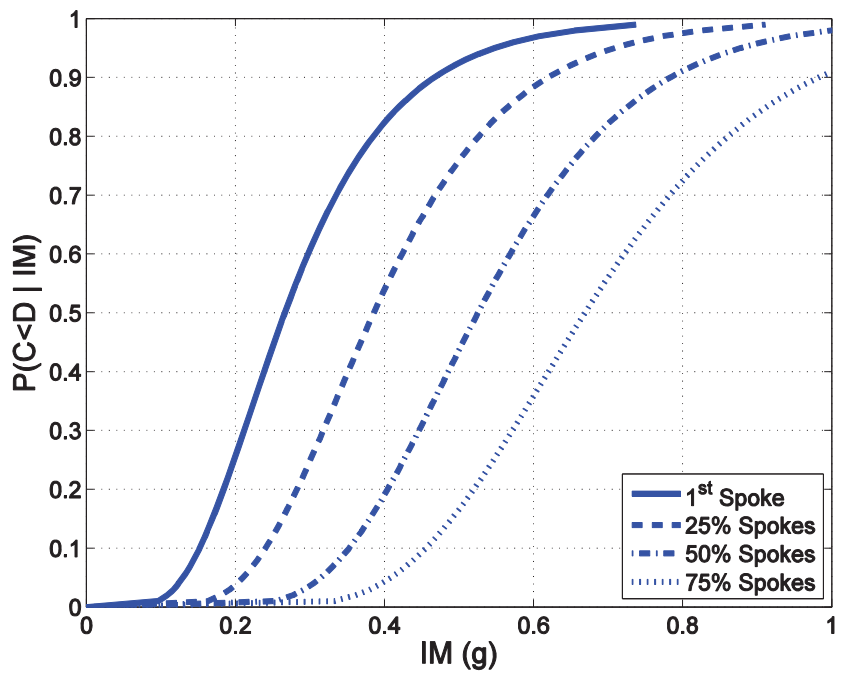

Fig. 10: DS3b fragility curves for various EFB lengths

Fragility curves are extracted for the extended global damage state classification, thus concluding the seismic reliability assessment procedure. DS3b is introduced to an existing assessment methodology in view of providing a more robust criterion that aims to involve extreme ground motion scenarios in the risk assessment procedure. Apart from DS3b, the fragility curves presented on Fig. 11 highlight the issue of nonsequential damage states that has already been discussed by Bakalis et al. [4]. It does not alter the well-known probability of exceedance estimation, yet it highlights uncertainties related to the available code standard median capacities and their application within a probabilistic framework.

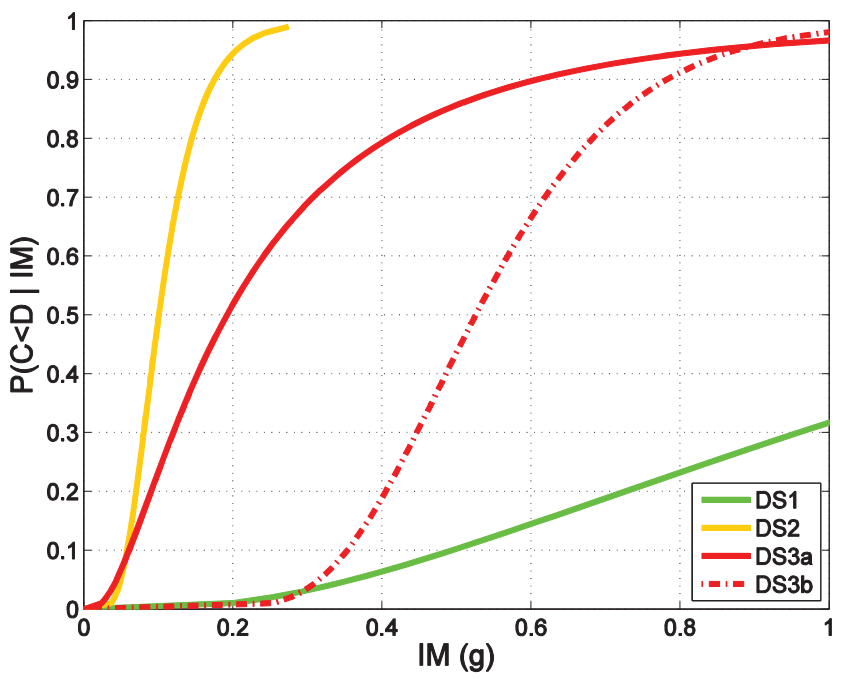

Fig. 11: Fragility curves featuring the Extended Global DS classification

\section{CONCLUSIONS}

A reliability assessment methodology has been developed for liquid storage tanks based on a surrogate, yet robust, beamelement model. Following the identification of failure modes through Incremental Dynamic Analysis, a local as well as a global damage state classification is defined, favouring the seismic risk assessment of either a single liquid storage system or an entire group of tanks, respectively. Special attention is paid on the elephant's foot buckling capacity and demand, while the associated effect on the assessment methodology is discussed. The reliability procedure utilises global damage states under a simplified probabilistic framework in order to assess the risk involved in liquid storage tanks. Fragility curves are provided in view of acknowledging the importance of the revised definition of the buckling manifestation. It appears that the EFB extend of damage presents a more detailed representation of the performance evaluation for liquid storage tanks. This approach attempts to enhance existing methodologies, while at the same time suggests that other modes of failure such as plastic rotation and sloshing damage should be examined on the same basis to provide more refined solutions.

\section{ACKNOWLEDGMENTS}

This research has been co-financed by the European Union (European Social Fund - ESF) and Greek national funds through the Operational Program "Education and Lifelong Learning" of the National Strategic Reference Framework (NSRF) - Research Funding Program: THALES. Investing in knowledge society through the European Social Fund.

\section{REFERENCES}

[1] Buratti, N., and Tavano, M., 2014, "Dynamic buckling and seismic fragility of anchored steel tanks by the added mass method," Earthq. Eng. Struct. Dyn., 43(1), pp. 121. 
[2] Talaslidis, D. G., Manolis, G. D., Paraskevopoulos, E., Panagiotopoulos, C., Pelekasis, N., and Tsamopoulos, J., 2004, "Risk analysis of industrial structures under extreme transient loads," Soil Dyn. Earthq. Eng., 24(6), pp. 435-448.

[3] O'Rourke, M. J., and So, P., 2000, "Seismic Fragility Curves for On- Grade Steel Tanks," Earthq. Spectra, 16(4), pp. 801-815.

[4] Bakalis, K., Vamvatsikos, D., and Fragiadakis, M., 2014, "Seismic Reliability Assessment of Liquid Storage Tanks," 2nd European Conference on Earthquake Engineering and Seismology, Istanbul, Turkey, 24-29 August 2014.

[5] CEN, 2006, Eurocode 8: Design of structures for earthquake resistance-Part 4: Silos, tanks and pipelines, Brussels.

[6] Vathi, M., Pappa, P., and Karamanos, S. A., 2013, "Seismic Response of Unanchored Liquid Storage Tanks," Proceedings of the ASME 2013 Pressure Vessels \& Piping Division Conference, Paris, France.

[7] Malhotra, P. K., and Veletsos, A. S., 1994, "Uplifting Response of Unanchored Liquid- Storage Tanks," J. Struct. Eng., 120(12), pp. 3525-3547.

[8] Vamvatsikos, D., and Cornell, C. A., 2002, "Incremental dynamic analysis,” Earthq. Eng. Struct. Dyn., 31(3), pp. 491-514.

[9] FEMA, 2009, Quantification of Building Seismic Performance Factors, FEMA P-695, prepared by Applied Technology Council for Federal Emergency Management Agency, Washington, D.C.

[10] Luco, N., and Cornell, C. A., 2007, "Structure-Specific Scalar Intensity Measures for Near-Source and Ordinary Earthquake Ground Motions," Earthq. Spectra, 23(2), pp. 357-392.

[11] Shafieezadeh, A., Ramanathan, K., Padgett, J. E., and DesRoches, R., 2012, "Fractional order intensity measures for probabilistic seismic demand modeling applied to highway bridges," Earthq. Eng. Struct. Dyn., 41(3), pp. 391-409. 